Int. J. Electrochem. Sci., 15(2020) 9335 - 9353

International Journal of

ELECTROCHEMICAL

SCIENCE

$\underline{\text { WwW.electrochemsci.org }}$

\title{
Evaluation of the effect of two Naproxen-Based Hydrazones on the corrosion inhibition of Mild Steel in $1.0 \mathrm{M} \mathrm{HCl}$
}

Maryam Chafiq ${ }^{1}$, Abdelkarim Chaouiki ${ }^{1}$, Mustafa R. Al-Hadeethi ${ }^{2}$, Hassane Lgaz ${ }^{3, *}$, Rachid Salghi ${ }^{1}$, Siham K. AbdelRaheem ${ }^{4}$, Ismat H. Ali ${ }^{4}$, Sara A. M. Ebraheem ${ }^{4}$, Shaaban K. Mohamed ${ }^{5,6}$, Ill-Min Chung ${ }^{3, *}$

${ }^{1}$ Laboratory of Applied Chemistry and Environment, ENSA, University Ibn Zohr, PO Box 1136, Agadir, Morocco;

${ }^{2}$ College of Education, Department of Chemistry, Kirkuk University, Kirkuk, Iraq;

${ }^{3}$ Department of Crop Science, College of Sanghur Life Science, Konkuk University, Seoul 05029,

South Korea

${ }^{4}$ Department of Chemistry, College of Science, King Khalid University, P. O. Box 9004, Postal Code 61413, Abha, Kingdom of Saudi Arabia;

${ }^{5}$ Chemistry and Environmental Division, Manchester Metropolitan University, Manchester, United

Kingdom;

${ }^{6}$ Chemistry Department, Faculty of Science, Minia University, El-Minia, Egypt;

*E-mail: hlgaz@konkuk.ac.kr (H. L.), imcim@konkuk.ac.kr (I-M. C.)

doi: $10.20964 / 2020.09 .69$

Received: 29 May 2020/ Accepted: 7 July 2020 / Published: 10 August 2020

During the past years, there has been an increasingly important emphasis on the study of corrosion inhibitors because of their performance in inhibiting the dissolution of metals in various corrosive mediums, making research into the use of environmentally safer substances a goal for corrosion scientists. On this wise, the anti-corrosive performance of (E)-N'-(4-chlorobenzylidene)-2-(6methoxynaphthalen-2-yl) propanehydrazide (CBMP) and ((E)-2-(6-methoxynaphthalen-2-yl)-N'-(4methylbenzylidene) propanehydrazide (MMBH) for mild steel (MS) in $1.0 \mathrm{M} \mathrm{HCl}$ has been studied employing electrochemical methods, weight loss and SEM/EDX examinations. An increase in the concentration of the inhibitor up to an optimized level of $5 \times 10^{-3} \mathrm{M}$ has significantly improved the corrosion rate $\left(i_{\text {corr }}\right)$ values. The preferential protective response of $\mathrm{MMBH}$ against corrosion has been investigated in a range of temperature settings of $303 \mathrm{~K}-333 \mathrm{~K}$. It is strongly implied by the results of the PDP experiments that the selected inhibitors acted as mixed-type inhibitors with a more pronounced cathodic nature. The adsorption of both compounds follows the Langmuir isotherm. $\mathrm{SEM} / \mathrm{EDX}$ confirmed the good inhibition performance of tested compounds.

Keywords: Corrosion inhibition; Mild steel; SEM/EDX; Electrochemical measurements. 
(C) 2020 The Authors. Published by ESG (www.electrochemsci.org). This article is an open access article distributed under the terms and conditions of the Creative Commons Attribution license (http://creativecommons.org/licenses/by/4.0/). 